\title{
Posterior Eye Segment
}

National Cancer Institute

\section{Source}

National Cancer Institute. Posterior Eye Segment. NCI Thesaurus. Code C12906.

The larger portion of the eye behind the lens containing the retina, vitreous humor, choroid, and optic nerve. 